\title{
Effects of celecoxib on cell apoptosis and Fas, FasL and Bcl-2 expression in a BGC-823 human gastric cancer cell line
}

\author{
QIAN LI, JIE PENG, TING LIU and GUIYING ZHANG \\ Department of Gastroenterology, Xiangya Hospital, Central South University, Changsha, Hunan 410008, P.R. China
}

Received May 17, 2016; Accepted March 13, 2017

DOI: $10.3892 /$ etm.2017.4769

\begin{abstract}
Fas, which is an apoptotic-related protein, has an important role in cell apoptosis. Fas ligand (FasL) binds to Fas and activates apoptosis signal transduction. We previously demonstrated that the efficiency of celecoxib inhibited the proliferation and apoptosis of HT-29 colon cancer cell line. The BGC823 cell line was used as an experimental model to evaluate the potential role of celecoxib on gastric cancer cell apoptosis. Inhibitory effects of celecoxib on cell viability were determined by MTT assay. Cell apoptosis was evaluated by flow cytometric analysis and laser confocal microscopy. The results of the present study demonstrated that celecoxib inhibited the viability of BGC823 cells in a concentration- and time-dependent manner. Furthermore, the effect of BGC823 cells apoptosis was increased in a concentration-dependent manner. Western blotting was used to determine the protein expression levels of Fas, FasL, and B-cell lymphoma-2 (Bcl-2). During the celecoxib-induced apoptosis of BGC823 cells, celecoxib upregulated Fas expression and downregulated FasL and $\mathrm{Bcl}-2$ expression in a concentration-dependent manner. These results suggest that celecoxib inhibited the growth and induced apoptosis of BGC823 gastric cancer cells by regulating the protein expression of Fas, FasL and Bcl-2.
\end{abstract}

\section{Introduction}

Apoptosis, called also cell suicide or programmed cell death, is a genetically directed process of cell self-destruction (1). Abnormal apoptosis is a component of the pathogenesis of most malignant tumors (1). Fas, a member of the tumor necrosis factor-R (TNF-R) family and a cell surface death receptor, may be an important protein for apoptosis that is induced by ligand binding, such as to Fas ligand (FasL), and

Correspondence to: Dr Qian Li or Dr Guiying Zhang, Department of Gastroenterology, Xiangya Hospital, Central South University, 87 Xiangya Road, Changsha, Hunan 410008, P.R. China

E-mail: liqian0816@sina.com

E-mail: gyzhang2013@163.com

Key words: celecoxib, Fas, Fas ligand, B-cell lymphoma-2, gastric cancer cell leads to subsequent activation of apoptotic signal transduction pathways (2-4). FasL (CD95L or APO-1L), belongs to the family of TNF-related cytokines. Repeated activation of antigen receptors on $\mathrm{T}$ cells induces FasL expression and leads to Fas-transduced apoptosis (5). Cytochrome $\mathrm{C}$ release is a critical step in the apoptotic cascade, which involves the release of cytochrome $\mathrm{C}$ into the cytosol where it binds with apoptotic protease-activating factor (Apaf-1) (6). Also, apoptotic pathways dependent on cytochrome $\mathrm{C}$ may be influenced by $\mathrm{Bcl}-2$, which can inhibit the release of cytochrome $\mathrm{C}$ and thereby inhibit cell apoptosis (7).

Our previous observations (8) that the cyclooxygenase-2 (COX-2) inhibitor, celecoxib, was able to inhibit viability in the BGC-823 gastric cancer cell line led us to investigate whether celecoxib could induce apoptosis in the same gastric cancer cell line and whether celecoxib modified expression of Fas, FasL, and Bcl-2, which regulate several aspects of apoptosis (9).

\section{Materials and methods}

Cell culture and treatment. The human BGC-823 gastric cancer cell line was obtained from Central South University Cancer Institute (Changsha, China). BGC-823 cells were cultured in RPMI-1640 supplemented with $10 \%$ fetal bovine serum (Beijing TianShiDai Inc., Beijing, China), and $100 \mathrm{U} / \mathrm{ml}$ penicillin/streptomycin (Nanjing KeyGen Biotech Co. Ltd., Nanjing, China). Cells were cultured at $37^{\circ} \mathrm{C}$ in a humidified atmosphere containing $5 \% \mathrm{CO}_{2}$. Celecoxib (Pfizer, Inc., New York, NY, USA) was a generous gift from Professor Guangsheng Zhang at the Second Xiangya Hospital, Central South University (Changsha, China). Celecoxib was dissolved in dimethyl sulfoxide (DMSO) when stored at $30 \mathrm{mmol} / 1\left(4^{\circ} \mathrm{C}\right)$ and was diluted to a final concentration of $0.4 \%$ in culture medium.

Cell viability analysis. Cell viability inhibition was measured using an MTT (Sigma-Aldrich, Merck KGaA, Darmstadt Germany) colorimetric method. Briefly, 2x10 $/ \mathrm{ml} \mathrm{BGC-823}$ gastric cancer cells/well were inoculated into 96-well culture plates, until they reached $80 \%$ confluence. Subsequently, various concentrations of celecoxib in DMSO $(20,40,60$, 80,100 and $120 \mu \mathrm{M}$ ) were added to the cell culture medium. Control groups included a blank control, treated with RPMI-1640 cell culture medium, and a DMSO control, treated 
with DMSO. Cells were cultured for 24, 48, and $72 \mathrm{~h}$ prior to incubation for $4 \mathrm{~h}$ with $0.5 \%$ MTT (20 $\mu \mathrm{l}$ per well). An ELISA (wavelength, $570 \mathrm{~nm}$ ) was performed to obtain optical density (OD) values. Each experiment was repeated three times. Cell viability inhibitory rate was calculated using the following formula: Cell viability inhibitory rate=1-(test group OD value-blank control OD value)/(DMSO control group OD value-blank control OD value).

Cell apoptosis analysis. Cells grown to $80 \%$ confluence were treated with celecoxib $(20,40,60,80,100$ and $120 \mu \mathrm{M})$. Cells were incubated for $48 \mathrm{~h}$ and cell suspensions were subsequently centrifuged $\left(350 \mathrm{x} \mathrm{g} ; 4^{\circ} \mathrm{C} ; 5 \mathrm{~min}\right)$. Following treatment, the cells were washed twice with phosphate-buffered saline (PBS) and resuspended with binding buffer to regulate cell concentration to $10^{6} / \mathrm{ml}$. Subsequently, the cell suspension was stained with Annexin V-phycoerythrin (PE)/7-aminoactinomycin D (7-AAD; Beijing Korad Biotech Co., Ltd.) according to the manufacturer's protocol, prior to incubation for $15 \mathrm{~min}$ at room temperature in the dark. A FACSVerse flow cytometer (BD Biosciences, San Jose, CA, USA) was used to analyze the population of Annexin V-positive and 7-AAD-negative early apoptotic cells. Confocal laser fluorescence microscopy was used to observe fluorescence signals from early apoptotic cells.

Western blot analysis. Since cells were almost inhibited by $120 \mu \mathrm{M}$ celecoxib (8), BGC-823 gastric cancer cells were only treated with $0,20,40,60,80$ and $100 \mu \mathrm{M}$ celecoxib for $48 \mathrm{~h}$, and used to measure Fas, FasL, and Bcl-2 protein expression levels via western blot analysis. Rabbit anti-human GAPDH (catalogue no. BA2913), Fas (catalogue no. PB0214), FasL (catalogue no. BA0049) and Bcl-2 (catalogue no. BA0412) monoclonal antibodies and goat anti-rabbit antibodies (catalogue no. BA1055) labeled with horseradish peroxidase were purchased from Boster Biological Technology, Ltd., (Wuhan, China). Proteins were extracted from the BGC-823 gastric cancer cell line, and protein quantification was performed using a bicinchoninic acid protein assay (Nanjing KeyGen Biotech Co., Ltd.) with bovine serum albumin as a standard. Proteins (30 $\mu \mathrm{g} / \mathrm{sample})$ in SDS-loading buffer were heated to $100^{\circ} \mathrm{C}$ for $5 \mathrm{~min}$, separated by $12 \%$ SDS-PAGE and transferred to a nitrocellulose membrane. The membrane was blocked overnight in 5\% nonfat dry milk in TBST buffer at $4^{\circ} \mathrm{C}$. Blots were then incubated at room temperature for $2 \mathrm{~h}$ with rabbit anti-human Fas, FasL, and Bcl-2 monoclonal antibodies (1:300) in TBST buffer with 5\% nonfat dry milk. Following washing in TBST buffer four times for $7 \mathrm{~min}$, blots were incubated for $1 \mathrm{~h}$ at room temperature with horseradish peroxidase-conjugated goat anti-rabbit IgG antibodies (1:800) in TBST buffer with $5 \%$ nonfat dry milk. Finally, membranes were washed three times and developed with enhance chemiluminescence reagent (Boster Biological Technology, Ltd.). Immunoreactive bands were quantified using ImageJ software (National Institutes of Health, Bethesda, MD, USA).

Statistical analysis. Data were processed by SPSS (version 15.0; SPSS, Inc., Chicago, IL, USA) statistical software. Data were represented as means \pm standard deviation and compared using one-way analysis of variance and Tukey's multiple

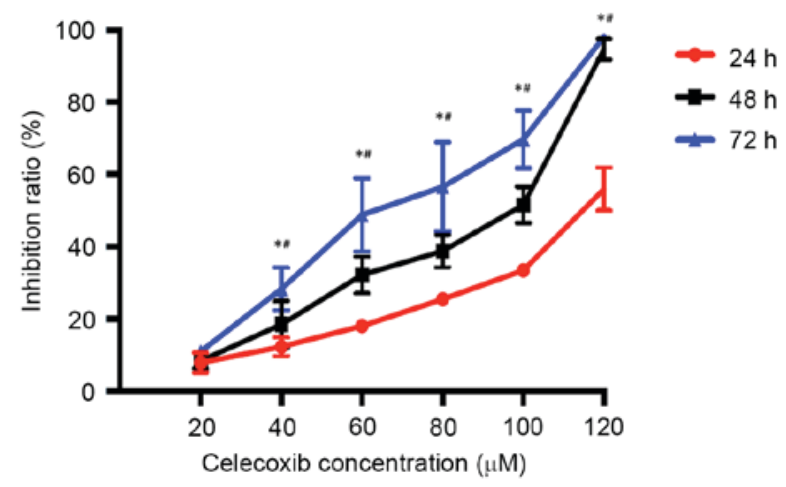

Figure 1. Celecoxib inhibited the viability of BGC-823 gastric cancer cells. Cells were treated with 0 (DMSO control), 20, 40, 60, 80, 100 and $120 \mu \mathrm{M}$ celecoxib for 24,48 and $72 \mathrm{~h}$. BGC-823 cell growth was measured using an MTT assay. Quantitative variables were expressed as the mean \pm standard deviation of three independent experiments. ${ }^{*} \mathrm{P}<0.05$ vs. $20 \mu \mathrm{M}$ group; ${ }^{\#} \mathrm{P}<0.001$ vs. $24 \mathrm{~h}$.

comparison test among groups. $\mathrm{P}<0.05$ was considered to indicate a statistically significant difference.

\section{Results}

Celecoxib inhibits the viability of BGC-823 gastric cancer cells. MTT analysis showed that celecoxib inhibited cell viability of BGC-823 gastric cancer cells in a time- and concentration-dependent manner $(\mathrm{P}<0.001$ and $\mathrm{P}<0.05$, respectively). Inhibition ratio of cell viability peaked at $98 \%$ at $120 \mu \mathrm{M}$ after $72 \mathrm{~h}$ (Fig. 1).

Celecoxib induces apoptosis in BGC-823 gastric cancer cells. Flow cytometric analysis revealed the effect of celecoxib on BGC-823 gastric cancer cell apoptosis. Intact cells were used as a blank control group. Remaining cells were treated with 0 (DMSO control), 20, 40, 60, 80, 100 and $120 \mu \mathrm{M}$ celecoxib concentration for $48 \mathrm{~h}$. In the $0,20,40,60,80,100$ and $120 \mu \mathrm{M}$ celecoxib concentration groups, the respective percentages of early apoptotic cells were $17.43 \pm 0.82,17.37 \pm 0.94,21.77 \pm 1.27$, $29.13 \pm 3.1,41.47 \pm 5.20,75.60 \pm 3.76$, and $88.37 \pm 3.27 \%$. These results suggested that celecoxib may induce BGC-823 gastric cancer cell apoptosis in a concentration-dependent manner (Fig. 2).

Apoptotic cells were also assessed by fluorescence-activated cell sorter analysis of Annexin V-PE/7-AAD staining. Nuclei were counterstained with DAPI. The percentage of early apoptotic cells and dead cells increased with the concentration of celecoxib (Fig. 3).

Celecoxib regulates the expression of Fas, FasL and Bcl-2 protein in BGC-823 gastric cancer cells. Cells were treated with $0,20,40,60,80$, and $100 \mu \mathrm{M}$ celecoxib for $48 \mathrm{~h}$. Western blot analysis verified that, with increased celecoxib concentration, FasL and Bcl-2 protein expression levels decreased, as demonstrated by thinner protein bands; whereas Fas protein expression increased, as demonstrated by thicker bands, in a concentration-dependent manner (Fig. 4). OD values for semi-quantitative determination of the relative protein content are depicted in Table I. 
A
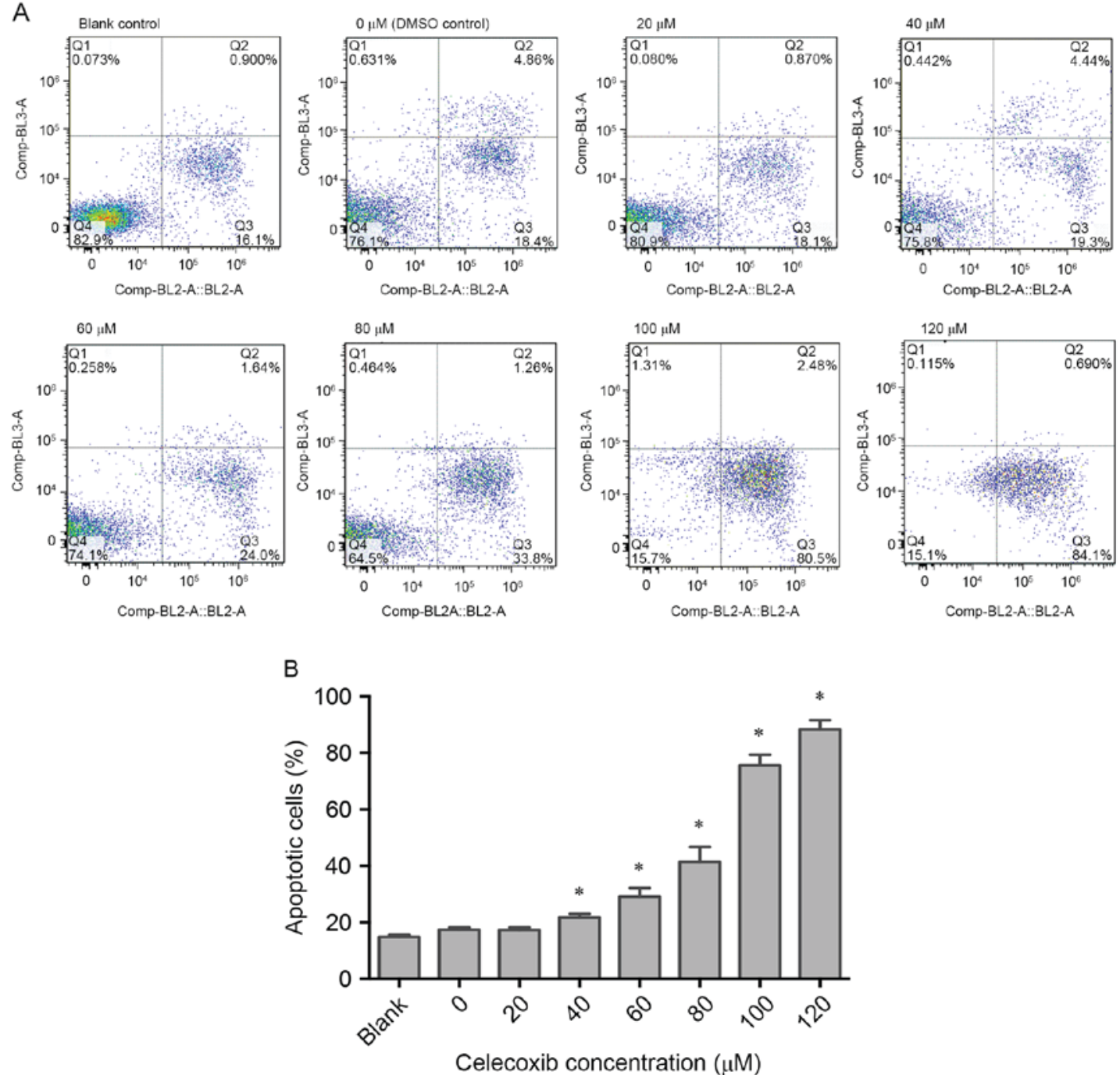

Figure 2. Flow cytometric analysis and subsequent quantification demonstrated the apoptosis effects of celecoxib on BGC-823 gastric cancer cells. (A) Cells were treated with 0 (DMSO control), 20,40,60,80,100 and $120 \mu \mathrm{M}$ celecoxib concentration for $48 \mathrm{~h}$. Cell were stained Annexin V-phycoerythrin/7-AAD. (B) Percentage of Annexin V-positive and 7-AAD-negative early apoptotic cells were derived from three independent experiments and expressed as the mean \pm standard deviation. " $\mathrm{P}<0.05$ vs. Blank (DMSO control). AAD, aminoactinomycin.

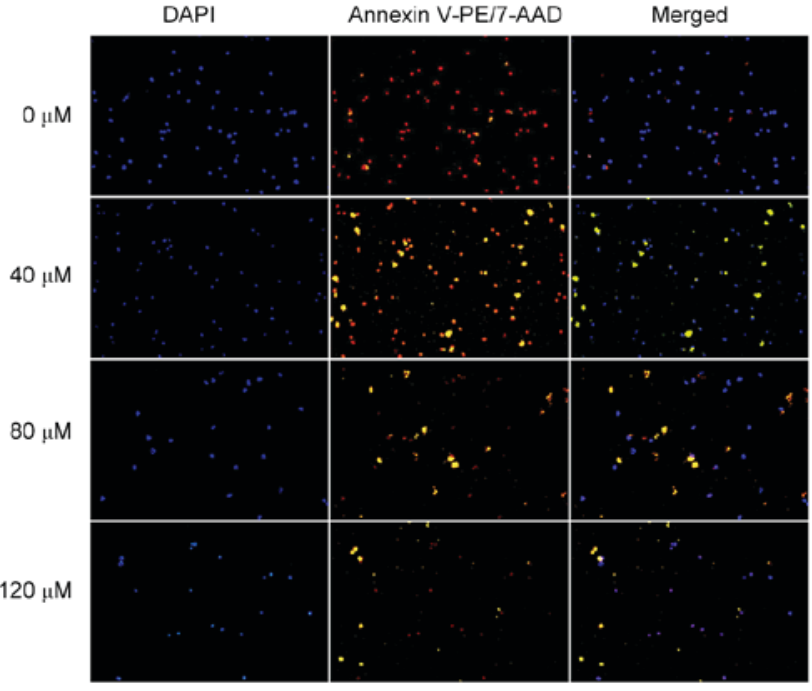

Figure 3. Confocal laser fluorescence microscopy demonstrated the early apoptosis effects of celecoxib on BGC-823 gastric cancer cells. DAPI counterstained the cells nuclei blue. Annexin V-PE/7-AAD stained early apoptotic cells orange. PE, phycoerythrin; AAD, aminoactinomycin.

\section{Discussion}

Cell proliferation and apoptosis are two critical cellular behaviors and their mechanisms are often the core of diseases or disorders. Uncontrolled cell proliferation or apoptosis can give rise to tumors as cancer research has shown that malignant cell proliferation involves abnormal apoptosis (10). Therefore, selective apoptosis of tumor cells may be a viable cancer treatment strategy.

Apoptosis, which is a type of programmed cell death, is a spontaneous biological process that follows a predetermined pathway. Cell volume shrinks, chromatin condenses, and the nucleus collapses. As the cell dies, unused nutrient macromolecules are transferred to neighboring cells. Apoptosis offers a unique perspective for tumor studies in which two apoptotic pathways exist $(11,12)$. One pathway is mediated by cell death receptors (tumor necrosis factor receptor or Fas) and caspase- 8 activation by Fas-associated death domain protein (FADD). The second pathway of apoptosis is induced by developmental signals or growth factor withdrawal, 
Table I. Fas, FasL and Bcl-2 protein expression in a BGC-823 gastric cancer cell line treated with various concentrations of celecoxib for $48 \mathrm{~h}(\mathrm{n}=3$; mean \pm standard deviation).

\begin{tabular}{llll}
\hline Concentration $(\mu \mathrm{M})$ & Fas/GAPDH & FasL/GAPDH & Bcl-2/GAPDH \\
\hline 0 & $0.1113 \pm 0.0037$ & $0.8070 \pm 0.0268$ & $0.5448 \pm 0.0049$ \\
20 & $0.1017 \pm 0.0065$ & $0.7311 \pm 0.0780^{\mathrm{a}}$ & $0.5213 \pm 0.0326$ \\
40 & $0.1975 \pm 0.0100^{\mathrm{a}}$ & $0.6254 \pm 0.0501^{\mathrm{a}}$ & $0.4322 \pm 0.0306^{\mathrm{a}}$ \\
60 & $0.3297 \pm 0.0053^{\mathrm{a}}$ & $0.5465 \pm 0.0180^{\mathrm{a}}$ & $0.3901 \pm 0.0264^{\mathrm{a}}$ \\
80 & $0.4595 \pm 0.0045^{\mathrm{a}}$ & $0.4378 \pm 0.0081^{\mathrm{a}}$ & $0.2659 \pm 0.0121^{\mathrm{a}}$ \\
100 & $0.5204 \pm 0.0148^{\mathrm{a}}$ & $0.3760 \pm 0.0034^{\mathrm{a}}$ & $0.2228 \pm 0.0071^{\mathrm{a}}$ \\
\hline
\end{tabular}

${ }^{\mathrm{a}} \mathrm{P}<0.05$ vs $0 \mu \mathrm{M}$. FasL, Fas ligand; Bcl-2, B-cell lymphoma-2.

A

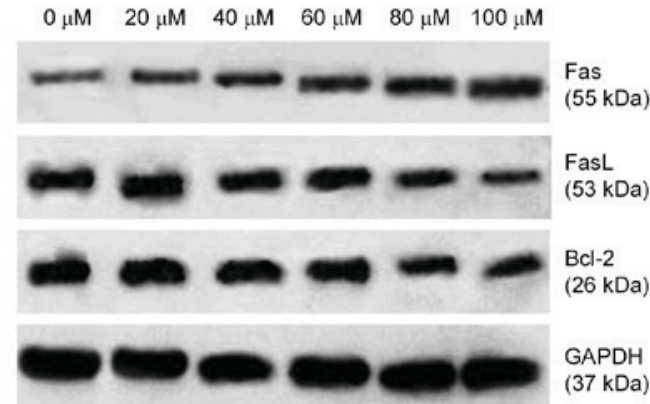

B

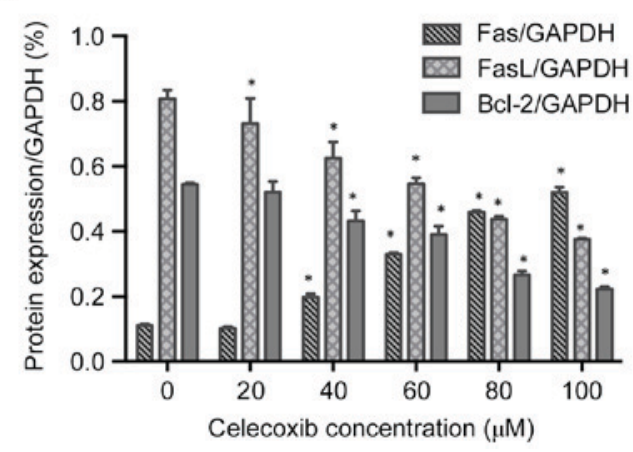

Figure 4. Celecoxib regulated the expression of apoptosis-related proteins in BGC-823 gastric cancer cells. Cells were treated with 0, 20, 40, 60, 80 and $100 \mu \mathrm{M}$ celecoxib for $48 \mathrm{~h}$ and subjected to (A) western blot analysis and (B) subsequent quantification. Data are expressed as the mean + standard deviation from three independent experiments. ${ }^{*} \mathrm{P}<0.05$ vs $0 \mu \mathrm{M}$.

which triggers cytochrome $\mathrm{C}$ release from mitochondria. Subsequently, apoptosis activated factor-1 (apoptotic protease activating factor-1) polymerization and caspase- 9 activation occur in a process controlled by a gene that regulates the $\mathrm{B}$ cell lymphoma/leukemia 2 (Bcl-2) protein family. Fas has an important role in cell apoptosis. Its ligand, FasL, binds and activates apoptosis signal transduction $(2,3)$.

Previous studies have suggested that non-steroidal anti-inflammatory drugs (NSAIDs), including indomethacin, tolfenamic acid and aspirin, are able to inhibit the occurrence and development of chemically-induced colon tumors, inhibit tumor cell growth and proliferation and increase tumor cell apoptosis (13-16). Previous studies suggest that the antitumor effect of NSAIDs are associated with cyclooxygenase (COX), specifically COX-2 (13), and this COX-2 inhibition may be the mechanism underlying the anti-tumor effect (17). Pang et al (18) reported that celecoxib induces apoptosis in gastric cancer cells that do not express COX-2. Zhu et al $(19,20)$ reported that traditional chemotherapy drugs combined with rofecoxib or with celecoxib reduce tumor chemoresistance, improve the overall curative effect, and may sensitize tumor cells to chemotherapy. The mechanism for this may be the induction of cancer cell apoptosis. Selective COX-2 inhibitors, such as nimesulide, NS-398 and celecoxib, have been reported to induce apoptosis in human colon cancer cells and liver cancer cells (21-23). Li et al (24) reported that nimesulide induced apoptosis in gastric cancer cells. These studies suggest that COX-2 inhibitors may induce tumor cell apoptosis, via the inhibition of COX-2. To investigate this hypothesis, we treated the BGC-823 gastric cancer cell line with celecoxib and used molecular biological techniques to measure gastric cancer cell apoptosis and the expression of apoptosis-related proteins.

Cell apoptosis, reduced cell volume, alterations in light scattering, membrane permeabilization can all be used to detect apoptotic cells. Cells suspended with fluorescein staining can be subjected to flow cytometry to detect apoptosis in living and fixed dead cells. By flow cytometry, Annexin $\mathrm{V}-\mathrm{PE}$ can be detected in the PE signal channel and 7-AAD can be detected in the red fluorescent channel. The analysis can be obtained by using two parameter scatter plots (25). The present findings demonstrated that apoptosis in the BGC-823 cell line was concentration-dependent when cells were treated with 20-120 $\mu \mathrm{M}$ celecoxib. Confocal laser fluorescence microscopy also indicated orange staining indicative of early apoptosis by conjugated staining.

Fas is a cell surface death receptor that binds FasL in order to be activated and signal apoptosis. T and natural killer (NK) cells are responsible for killing tumor cells (26). Some cytokines, chemotherapy and radiation therapy can increase tumor cell surface expression of Fas, inducing apoptosis of tumor cells (27). Williams (28) has reported that chemotherapeutics, such as Adriamycin, act on tumors via apoptosis and increase Fas and FasL expression in tumor cells, promoting tumor cell death. Thus, increasing FasL expression in lymphocytes or the application of Fas-specific monoclonal antibodies may be a promising chemotherapeutic strategy at the gene level. Enhanced expression of Fas and FasL may enhance killer immune cell function against tumor cells as well as inhibit tumor cell immunity so that cancerous cells cannot 'fight back' (28). 
FasL is predominantly expressed in cytotoxic $\mathrm{T}$ lymphocytes, NK cells and some immune tissue (29). FasL expressed in these cells binds to Fas-positive cells to initiate the death signal and apoptosis. Fas expression in benign tumors is similar to normal tissues; whereas Fas expression in malignant tumors is downregulated or lost, and in metastatic tumors is decreased (30). Malignant tumors lacking Fas escape the scavenging effect of the Fas:FasL system in vivo (30). Tumor cells with high FasL expression, such as immune tissue, protect themselves from active killer immune cells. Expression of the Fas antigen in immune cells can trigger apoptotic mechanisms by expression of Fasl in tumor cells (31-33).

Human BGC-823 gastric cancer cells treated with celecoxib for $48 \mathrm{~h}$ were found to have less FasL protein expression. The Fas and FasL apoptotic system may mediate apoptosis in this cancer cell line, increasing Fas expression and the activation of FADD (34), which activates the caspase- 8 cascade and cancer cell apoptosis. Celecoxib treatment of gastric cancer cells with low FasL expression can reduce immunologically active cells induced by apoptosis, facilitating immune cells' ability to kill tumor cells (29). Apoptotic pathways are dependent on cytochrome $c$, and data show that mitochondria are important in apoptosis. The cell apoptosis Bcl-2 family is primarily located in the mitochondrial membrane. Cytochrome $c$ is released into the cytosol after mitochondria permeability transition pores (MPT) open to promote apoptosis. The Bcl-2 gene within the mitochondria can promote mitochondrial membrane stability, and block MPT opening and inhibiting cytochrome $c$ release, thereby inhibiting the apoptosis of cells (35-37). Zhang et al (38) revealed that COX-2 inhibitors downregulated the Bcl-2 gene in a colorectal HT-29 cancer cell line. Thus, Bcl-2 may have regulatory functions in the process of apoptosis that is dependent on cytochrome $c$. Our data are in agreement with these findings. Bcl-2 protein expression was downregulated with celecoxib treatment in a dose-dependent manner, reducing the inhibitory effect on apoptosis in a human BGC-823 gastric cancer cell line, thereby promoting apoptosis of cancer cells.

In conclusion, the present findings demonstrated that celecoxib treatment increased expression of Fas protein and decreased FasL protein expression, suggesting that these two molecules are important in apoptotic signaling. Bcl-2 protein expression was downregulated by celecoxib treatment, suggesting that this, too, may be important in apoptotic signal transduction pathways that depend on cytochrome $c$. Regulation of apoptosis is complex, and non-COX-2 dependent pathways may exist. Therefore, further studies are warranted to investigate the molecular mechanism related to protein expression and of celecoxib-induced apoptosis.

\section{Acknowledgements}

This study was supported by a grant from the Natural Science Foundation of China (grant no. 81272735).

\section{References}

1. Elmore S: Apoptosis: A review of programmed cell death Toxicol Pathol 35: 495-516, 2007.
2. Parlato S, Giammarioli AM, Logozzi M, Lozupone F, Matarrese P, Luciani F, Falchi M, Malorni W and Fais S: CD95 (APO-1/Fas) linkage to the actin cytoskeleton through ezrin in human T lymphocytes: A novel regulatory mechanism of the CD95 apoptotic pathway. EMBO J 19: 5123-5134, 2000

3. Schneider P, Bodmer JL, Holler N, Mattmann C, Scuderi P, Terskikh A, Peitsch MC and Tschopp J: Characterization of Fas (Apo-1, CD95)-Fas ligand interaction. J Biol Chem 272: 18827-18833, 1997.

4. Ashkenazi A and Dixit VM: Death receptors: Signaling and modulation. Science 281: 1305-1308, 1998.

5. Tanaka M, Itai T, Adachi M and Nagata S: Downregulation of Fas ligand by shedding. Nat Med 4: 31-36, 1998.

6. Hüttemann M, Pecina P, Rainbolt M, Sanderson TH, Kagan VE, Samavati L, Doan JW and Lee I: The multiple functions of cytochrome $\mathrm{c}$ and their regulation in life and death decisions of the mammalian cell: From respiration to apoptosis. Mitochondrion 11: 369-381, 2011.

7. Yin XM: Signal transduction mediated by Bid, a pro-death Bcl-2 family proteins, connects the death receptor and mitochondria apoptosis pathways. Cell Res 10: 161-167, 2000.

8. Li Q, Peng J and Zhang GY: Effect of a selective COX-2 inhibitor on cell proliferation and apoptosis in human gastric cancer cell line BGC-823. Zhong Nan Da Xue Xue Bao Yi Xue Ban 33: 1123-1128, 2008 (In Chinese).

9. Liang CZ, Zhang JK, Shi Z, Liu B, Shen CQ and Tao HM: Matrine induces caspase-dependent apoptosis in human osteosarcoma cells in vitro and in vivo through the upregulation of Bax and Fas/FasL and downregulation of Bcl-2. Cancer Chemother Pharmacol 69: 317-331, 2012.

10. Wong RS: Apoptosis in cancer: From pathogenesis to treatment. J Exp Clin Cancer Res 30: 87, 2011.

11. Fatima N, Yi M, Ajaz S, Stephens RM, Stauffer S, Greenwald P, Munroe DJ and Ali IU: Altered gene expression profiles define pathways in colorectal Cancer cell lines affected by celecoxib. Cancer Epidemiol Biomarkers Prev 17: 3051-3061, 2008.

12. Li Jianying and $\mathrm{Yu}$ Jieping: Influence of Selective Cyclooxygenase-2 Inhibitor on Proliferation of Human Gastric Carcer Cells. Zhong Guo Ai Zheng Za Zhi 6: 625-629, 2002.

13. Jankowski $\mathrm{J}$ and Hunt R: Cyclooxygenase-2 inhibitors in colorectal cancer prevention: Counterpoint. Cancer Epidemiol Biomarkers Prev 17: 1858-1861, 2008.

14. Makar KW, Poole EM, Resler AJ, Seufert B, Curtin K, Kleinstein SE, Duggan D, Kulmacz RJ, Hsu L, Whitton J, et al: COX-1 (PTGS1) and COX-2 (PTGS2) polymorphisms, NSAID interactions and risk of colon and rectal cancers in two independent populations. Cancer Causes Control 24: 2059-2075, 2013.

15. Basha R, Baker CH, Sankpal UT, Ahmad S, Safe S, Abbruzzese JL and Abdelrahim M: Therapeutic applications of NSAIDS in cancer: Special emphasis on tolfenamic acid. Front Biosci (Schol Ed) 3: 797-805, 2011.

16. Rothwell PM, Price JF, Fowkes FG, Zanchetti A, Roncaglioni MC, Tognoni G, Lee R, Belch JF, Wilson M, Mehta Z and Meade TW: Short-term effects of daily aspirin on cancer incidence, mortality and non-vascular death: Analysis of the time course of risks and benefits in 51 randomised controlled trials. Lancet 379: 1602 , 2012.

17. Cha YI and DuBois RN: NSAIDs and Cancer Prevention: Targets Downstream of COX-2. Annu Rev Med 58: 239-252, 2007.

18. Pang Ruiping, Hu Pinjin, Zeng Zhirong and Chen Wei: Celecoxib induces apoptosis of gastric cancer cells without expression of cyclooxygenase-2. Chinese Journal of pathophysiology 22: 842-845, 2006 (In Chinese).

19. Zhu Fengshang, Chen Ximei, Wang Yijun and Zhang Xia: Effects of a specific cyclooxygenase inhibitor Rofecoxib on reversing intrinsic drug resistance of gastric cancer BGC-823. Tong Ji Da Xue Xue Bao (Yi Xue Ban) 28: 25-29, 2007.

20. Zhu Fengshang, Chen Ximei, Wang, Yijun and Zhang Xia: Study on the mechanism of cancer chemotherapy drug efficacy of celecoxib enhances. Zhong Guo Lin Chuang Yao Li Xue Za Zhi 24: 237-239, 2008.

21. Zhong B, Cai X, Chennamaneni S, Yi X, Liu L, Pink JJ, Dowlati A, Xu Y, Zhou A and Su B: From COX-2 inhibitor nimesulide to potent anti-cancer agent: Synthesis, in vitro, in vivo and pharmacokinetic evaluation. Eur J Med Chem 47: 432-444, 2012.

22. Cheng AS, Chan HL, Leung WK, To KF, Go MY, Chan JY, Liew CT and Sung JJ: Expression of HBx and COX-2 in chronic hepatitis B, cirrhosis and hepatocellular carcinoma: Implication of HBx in upregulation of COX-2. Xian Dai Bing Li Xue 17: $1169-1179,2004$. 
23. Zhang $\mathrm{Z}$ and DuBois RN: Par-4, a proapoptotic gene, is regulated by NSAIDs in human colon carcinoma cells. Gastroenterology 118: 1012-1017, 2000.

24. Li S, Tong Q, Zhang W, Wang Q, Chen Z and Wu Q: Mechanism of growth inhibitory effects of cyclooxygenase-2 inhibitor-NS398 on cancer cells. Cancer Invest 26: 333-337, 2008.

25. Jin $X$ and Shi YI: Isobavachalcone induces the apoptosis of gastric cancer cells via inhibition of Akt and Erk pathways. Exp Ther Med 11: 403-408, 2016

26. Imtiyaz HZ, Rosenberg S, Zhang Y, Rahman ZS, Hou YJ, Manser $\mathrm{T}$ and Zhang $\mathrm{J}$ : The fas-associated death domain protein is required in apoptosis and TLR-induced proliferative responses in B cells. J Immunol 176: 6852-6861, 2006.

27. Goel A, Dispenzieri A, Greipp PR, Witzig TE, Mesa RA and Russell SJ: PS-341-mediated selective targeting of multiple myeloma cells by synergistic increase in ionizing radiation-induced apoptosis. Exp Hematol 33: 784-795, 2005.

28. Williams N: Tumor cells fight back to beat immune system. Science 274: 1302, 1996.

29. Smyth MJ, Cretney E, Kelly JM, Westwood JA, Street SE, Yagita H, Takeda K, van Dommelen SL, Degli-Esposti MA and Hayakawa Y: Activation of NK cell cytotoxicity. Mol Immunol 42: 501-510, 2005.

30. Fulda S: Tumor resistance to apoptosis. Int J Cancer 124: 511-515, 2009.

31. Lim SC: Fas-related apoptosis in gastric adenocarcinoma. Oncol Rep 10: 57-63, 2003.

32. Takahama Y, Yamada Y, Emoto K, Fujimoto H, Takayama T, Ueno M, Uchida H, Hirao S, Mizuno T and Nakajima Y: The prognostic significance of overexpression of the decoy receptor for Fas ligand (DcR3) in patients with gastric carcinomas. Gastric Cancer 5: 61-68, 2002.
33. Yaqub S, Henjum K, Mahic M, Jahnsen FL, Aandahl EM, Bjørnbeth BA and Taskén K: Regulatory T cells in colorectal cancer patients suppress anti-tumor immune activity in a COX-2 dependent manner. Cancer Immunol Immunother 57: 813-821, 2008.

34. Scott FL, Stec B, Pop C, Dobaczewska MK, Lee JJ, Monosov E, Robinson H, Salvesen GS, Schwarzenbacher R and Riedl SJ: The Fas-FADD death domain complex structure unravels signalling by receptor clustering. Nature 457: 1019-1022, 2009.

35. Chipuk JE, Fisher JC, Dillon CP, Kriwacki RW, Kuwana T and Green DR: Mechanism of apoptosis induction by inhibition of the anti-apoptotic BCL-2 proteins. Proc Natl Acad Sci USA 105: 20327-20332, 2008.

36. Tsujimoto Y and Shimizu S: Bcl-2 family: Life-or-death switch. FEBS Lett 466: 6-10, 2000.

37. Marsden VS, O'Connor L, O'Reilly LA, Silke J, Metcalf D, Ekert PG, Huang DC, Cecconi F, Kuida K, Tomaselli KJ, et al: Apoptosis initiated by Bcl-2-regulated caspase activation independently of the cytochrome c/Apaf-1/caspase-9 apoptosome. Nature 419: 634-637, 2002.

38. Zhang Youcheng, Wang Shan, Zhang Hui, Liang Bin and Ye Yingjiang: Mechanism of signal transducer and activator of transcription 3 signal transduction pathway of selective cyclooxygenase 2 inhibitor against colon cancer. Chin J Gastro Surg 7: 404-440, 2004 